\title{
Interaction of Shoot Emergence Date and Long Days after Controlled-temperature forcing of 'Nellie White' Easter Lilies
}

\author{
John M. Dole ${ }^{1}$ \\ Department of Horticulture and Landscape Architecture, Oklahoma State University, Stillwater, \\ OK 74078
}

\begin{abstract}
Additional index words. bulb maturity, bulbs, flowering, Lilium longiflorum, photoperiod
Abstract. 'Nellie White' Easter lily bulbs (Lilium longiflorum Thunb.) were given 6 weeks of 5.5C, placed in the greenhouse, and divided into groups based on number of days to emergence: 0 to 6, 7 to 13, 14 to 20, or 21 to 27 days. At emergence, the shoots received $0,1,2$, or 3 weeks of long days (LDs). The experiment was repeated for 3 consecutive years. Late-emerging plants had fewer days from emergence to visible bud and anthesis than early-emerging plants. Consequently, late-emerging plants flowered within 3 to 11 days of early emerging plants despite 16 to 22 days difference in emergence time. Late-emerging plants were tallest, while plants emerging in the second week had the most leaves. Flower count was not influenced by emergence date in Year 1. In Year 2, flower count decreased curvilinearly with later emergence. In Year 3, flower count was highest in plants emerging in the second week and lowest in the last week. Increasing LDs decreased the number of days from emergence to visible bud and anthesis but increased plant height. LDs did not affect leaf count in any year or flower count in Years 1 and 2. In Year 3, flower count increased with increasing weeks of LDs. LD $\times$ emergence date interactions existed, but varied from year to year.
\end{abstract}

The control of Easter lily growth and development is critical for forcers due to the varying date of Easter from year to year. Current recommendations suggest an "insurance policy" consisting of 1 to 3 weeks of long days (LDs) after 6 weeks of a cold, moist treatment to ensure flower induction (De Hertogh, 1989; Weiler, 1992; Wilkins, et al., 1970). One week is normally used on early- and 3 weeks on late-emerging plants, especially if Easter is early.

Many researchers have examined the effects of LDs applied after bulbs have received a cold treatment from emergence to anthesis (Kohl and Nelson, 1963; Smith and Langhans, 1962; Weiler and Langhans, 1968, 1972) or from 30 to 45 days after emergence (Heins et al., 1982; Roh and Wilkins, 1977; Wilkins et al., 1968a, 1968b) and found a decrease in the number of days to anthesis and an increase in height. While Weiler and Langhans $(1968,1972)$ reported that LDs decreased the number of leaves, Kohl and Nelson (1963) and Smith and Langhans (1962) found leaf count to be unaffected by LDs. Heins et al. (1982) found that 10-day intervals of LDs at various times during a 40-day period after emergence increased height, but did not change flower count. Conversely, Roh and Wilkins (1977) and Smith and Langhans (1962) noted a decreased flower count with LDs produced from incandescent sources. However, the effects of 1 to 3 weeks of LDs after 6 weeks of cold exposure has not been determined specifically.

Adding to the difficulty of forcing Easter lilies is the yearly variation in the date of Easter lily shoot emergence (Roberts et al., 1978). While increasing durations of cold treatment before greenhouse forcing decreased the number of days to emergence and number of days from first to last emerging shoot (De Hertogh and Wilkins, 1971a, 1971b; Stuart, 1954; Wilkins, 1980), the precise effects of emergence date on growth and development is not

Received for publication 2 Nov. 1992. Accepted for publication 15 Apr. 1993. Oklahoma Agricultural Experiment Station Journal series no. J6351. I thank Royal Heins and Harold Wilkins for their ideas and discussion; Randall Smith for his assistance with data collection; and the Easter Lily Research Foundation, Brooking-Harbor, Ore., for bulb donations. The cost of publishing this paper was defrayed in part by the payment of page charges. Under postal regulations, this paper therefore must be hereby marked advertisement solely to indicate this fact. ${ }^{1}$ Assistant professor. known. The objectives of this study were to determine the effects and interactions of 0 to 3 weeks of LDs and variable emergence dates on forced Easter lilies.

\section{Materials and Methods}

Year 1. 'Nellie White' Easter lily bulbs (20 to $23 \mathrm{~cm}$ in circumference) were received on 28 Oct. 1989 and held at $18.0 \pm$ $0.5 \mathrm{C}$ until they were planted 2 days later. At that time, bulbs were dipped in a solution containing commercial miticide and fungicides (Wilkins, 1988). Bulbs were planted in $15 \mathrm{~cm}$-diameter (1720-ml) pots using a commercial peat-perlite-vermiculite medium (Growing Mix No. 2, Conrad Fafard, Springfield, Mass.). Bulbs initially were held at $18.0 \pm 0.5 \mathrm{C}$ for rooting and, 15 days later, the temperature was reduced to $5.5 \pm 0.5 \mathrm{C}$ for 6 weeks.

On 27 Dec., bulbs were placed in a fiberglass-reinforced plastic-covered greenhouse set at 23.0/18.0C (day/night) with daily variations of $+12.5 / 3.1$ or $-5.1 / 4$.7C. Pots with emerged shoots were split randomly into four groups for treatment with 0 , 1,2 , or 3 weeks of LDs at 26.7/17.2 \pm 8.8/3.9C (day/night). LDs were applied by a 4-h night interruption (2200 to $0200 \mathrm{HR}$ ) from incandescent lamps (minimum of $12 \mu \mathrm{mol} \cdot \mathrm{m}^{-2} \cdot \mathrm{s}^{-1}$ photosynthetically active radiation). The remaining pots were checked daily for shoot emergence and, when four plants (or a multiple thereof) had emerged, they were placed randomly into the daylength treatments. If only one to three plants emerged, they remained under natural daylengths (lat. $36^{\circ} 07^{\prime} \mathrm{N}$ ) until at least four had emerged. After the LD treatment, plants were returned to natural daylengths.

The following data were collected at the date of anthesis: plant height (measured from the medium to top of the tallest pedicel) and leaf and flower counts. Dates of shoot emergence and visible bud also were recorded.

The design consisted of a completely randomized factorial with weeks of LDs and emergence groups as the main components. Plants were separated into emergence groups based on date of shoot emergence after placement in the greenhouse: $1=0$ to 6 days, $2=7$ to 13 days, $3=14$ to 20 days, or $4=21$ to 28 days. Plants were considered single unit replications. 
Year 2. 'Nellie White' Easter lily bulbs (20 to $23 \mathrm{~cm}$ in circumference) were received on 20 Oct. 1990 and planted 2 days later. Bulbs initially were held at $18.0 \pm 0.5 \mathrm{C}$ for rooting and, 15 days later, the temperature was reduced to $5.5 \pm 0.5 \mathrm{C}$ for 6 weeks. All other procedures were similar to those for Year 1.

Year 3. 'Nellie White' Easter lily bulbs (20 to $23 \mathrm{~cm}$ in circumference) were received on 26 Oct. 1991 and planted 6 days later. Bulbs initially were held at $18.0 \pm 0.5 \mathrm{C}$ for rooting and, 17 days later, the temperature was reduced to $5.5 \pm 0.5 \mathrm{C}$ for 6 weeks. All other procedures were similar to those for Year 1.

\section{Results}

Days from emergence to visible bud. In Year 2, days to visible bud from shoot emergence decreased with increasing weeks of LDs and delayed emergence (Table 1, Fig. 1B). A similar trend was noted in Year 3, except interactions existed between LDs and the emergence group, such that Group 1 plants that received 1 week of LDs had the most days to visible bud while Group 4 plants with 3 weeks of LDs had the fewest (Table 2, Fig. 2B). Results for Year 1 (data not presented) were similar to those for Year 3.

Days from visible bud to anthesis. Inconsistent results were obtained between years. The number of days from visible bud to anthesis for Year 2 was related curvilinearly to weeks of LDs and emergence dates, and interactions existed (Table 1, Fig. 1C). In Year 3, days to anthesis from visible bud increased linearly with delayed shoot emergence, but was not affected by LDs (Table 2, Fig. 2C). In Year 1 (data not presented), days to anthesis increased with weeks of LDs as in Year 2, but was not influenced by shoot emergence date and no interactions existed.

Days to anthesis from placement in the greenhouse. Days to anthesis decreased curvilinearly with increasing weeks of LDs, but increased with later emergence in Year 1 (data not presented) and Year 3 (Table 2, Fig. 2D). A similar trend was noted for Year 2, except that all responses were linear (Table 1, Fig. 1D). Interactions were found in all years, such that Group 4 plants that received no LDs took the most days to reach anthesis, while Group 1 plants that received 3 weeks of LDs reached anthesis in the fewest days (Tables 1 and 2).

Total plant height. Total plant height increased curvilinearly with increasing weeks of LDs and later emergence in all years and there were variable interactions (Tables 1 and 2, Fig. 1E, Fig. 2E, data not presented for Year 1).

Leaf count. In all years, leaf count was related curvilinearly to emergence date (Tables 1 and 2, Fig. 1F, Fig. 2F, data not presented for Year 1). Group 2 plants had the most leaves. Leaf count was not affected by LDs and no interactions existed in any year.

Flower count. In Year 2, there was a significant interaction between emergence date and LDs (Table 1, Fig. 1G). The most flowers were on Group 2 plants, which were treated with 1 week of LDs. In Year 3, flower count was highest for Group 2 plants, lowest for Group 4 plants, and generally increased with weeks of LDs (Table 2, Fig. 2G). Flower count was similar for all treatments in Year 1 (data not presented).

\section{Discussion}

LDs reduced the number of days to anthesis but increased height (Table 1, Fig. 1), a response that was consistent with results of previous reports (Heins et al., 1982; Roh and Wilkins, 1977). Plants treated with 3 weeks of LDs flowered 2 to 5 days earlier and were 2.9 to $5.2 \mathrm{~cm}$ taller than control plants not receiving LDs (Tables 1 and 2, Fig. 1D and E, Fig. 2 D and E). One or 2 weeks of LDs produced intermediate results. The decrease in days to anthesis was not due to fewer leaves, since it was not significantly affected by LD treatments. This response was similar to results obtained by Kohl and Nelson (1963) and Smith and Langhans (1962). The time from emergence to visible bud accounted for the

Table 1. Main effects and trend analysis of 0 to 3 weeks of long days (LDs) and emergence groups on 'Nellie White' Lilium longiflorum, Year 2 (1990-91).

\begin{tabular}{|c|c|c|c|c|c|c|c|c|}
\hline $\begin{array}{l}\text { Weeks of } \\
\text { LDs after } \\
\text { emergence }\end{array}$ & $\begin{array}{c}\text { Emergence } \\
\text { group }^{z}\end{array}$ & $\begin{array}{l}\text { No. of } \\
\text { plants }\end{array}$ & $\begin{array}{l}\text { Days from } \\
\text { emergence to } \\
\text { visible bud }\end{array}$ & $\begin{array}{l}\text { Days from } \\
\text { visible bud } \\
\text { to anthesis }\end{array}$ & $\begin{array}{l}\text { Days to } \\
\text { anthesis }^{y}\end{array}$ & $\begin{array}{l}\text { Plant } \\
\text { height } \\
(\mathrm{cm})\end{array}$ & $\begin{array}{l}\text { Leaf } \\
\text { count }\end{array}$ & $\begin{array}{c}\text { Flower } \\
\text { count }\end{array}$ \\
\hline$\overline{0}$ & Averaged & 46 & 50.6 & 34.0 & 97.9 & 36.0 & 76.1 & 6.2 \\
\hline 1 & Averaged & 48 & 49.0 & 34.0 & 97.7 & 35.5 & 76.8 & 6.3 \\
\hline 2 & Averaged & 45 & 48.9 & 33.1 & 96.7 & 37.7 & 78.8 & 6.5 \\
\hline 3 & Averaged & 46 & 46.9 & 34.6 & 96.0 & 41.2 & 76.9 & 6.1 \\
\hline \multirow[t]{4}{*}{ Averaged } & 1 & 22 & 60.4 & 34.1 & 95.2 & 35.3 & 79.9 & 7.0 \\
\hline & 2 & 31 & 51.0 & 33.8 & 96.1 & 37.9 & 81.2 & 6.7 \\
\hline & 3 & 114 & 46.9 & 33.9 & 97.5 & 37.7 & 76.1 & 6.1 \\
\hline & 4 & 19 & 42.1 & 34.2 & 98.3 & 39.0 & 72.1 & 5.7 \\
\hline \multicolumn{9}{|l|}{ Weeks of LDs (W) } \\
\hline Linear (L) & & & $0.0001^{x}$ & NS & 0.003 & 0.0001 & NS & NS \\
\hline Quadratic (Q) & & & NS & 0.022 & NS & 0.003 & NS & NS \\
\hline Residual (R) & & & NS & 0.030 & NS & NS & NS & NS \\
\hline \multicolumn{9}{|l|}{ Emergence group (E) } \\
\hline $\mathrm{L}$ & & & 0.0001 & NS & 0.0007 & 0.002 & 0.0001 & 0.0001 \\
\hline $\mathrm{Q}$ & & & 0.004 & NS & NS & NS & NS & NS \\
\hline- & & & 0.005 & NS & NS & NS & NS & NS \\
\hline Significant interactions & & & None & $\mathbf{L} \times \mathbf{L}$ & $\mathrm{L} \times \mathrm{L}$ & $\mathrm{L} \times \mathrm{Q}$ & None & $L \times Q$ \\
\hline$(\mathrm{W} \times \mathrm{E}, P \leq 0.05)$ & & & & $\mathrm{Q} \times \mathrm{R}$ & & $\mathrm{Q} \times \mathrm{L}$ & & $\mathrm{R} \times \mathrm{L}$ \\
\hline & & & & $\mathrm{R} \times \mathrm{Q}$ & & $\mathrm{Q} \times \mathrm{R}$ & & $\mathbf{R} \times \mathbf{Q}$ \\
\hline
\end{tabular}

${ }^{\text {ZEaster lily plants were separated into four groups based on date of emergence after controlled-temperature forcing and subsequent placement in the }}$ greenhouse: $1=0$ to $6,2=7$ to $13,3=14$ to $20,4=21$ to 27 .

yFrom date of placement in greenhouse.

${ }^{x}$ Significance level $(P)$; NS = nonsignificant. 

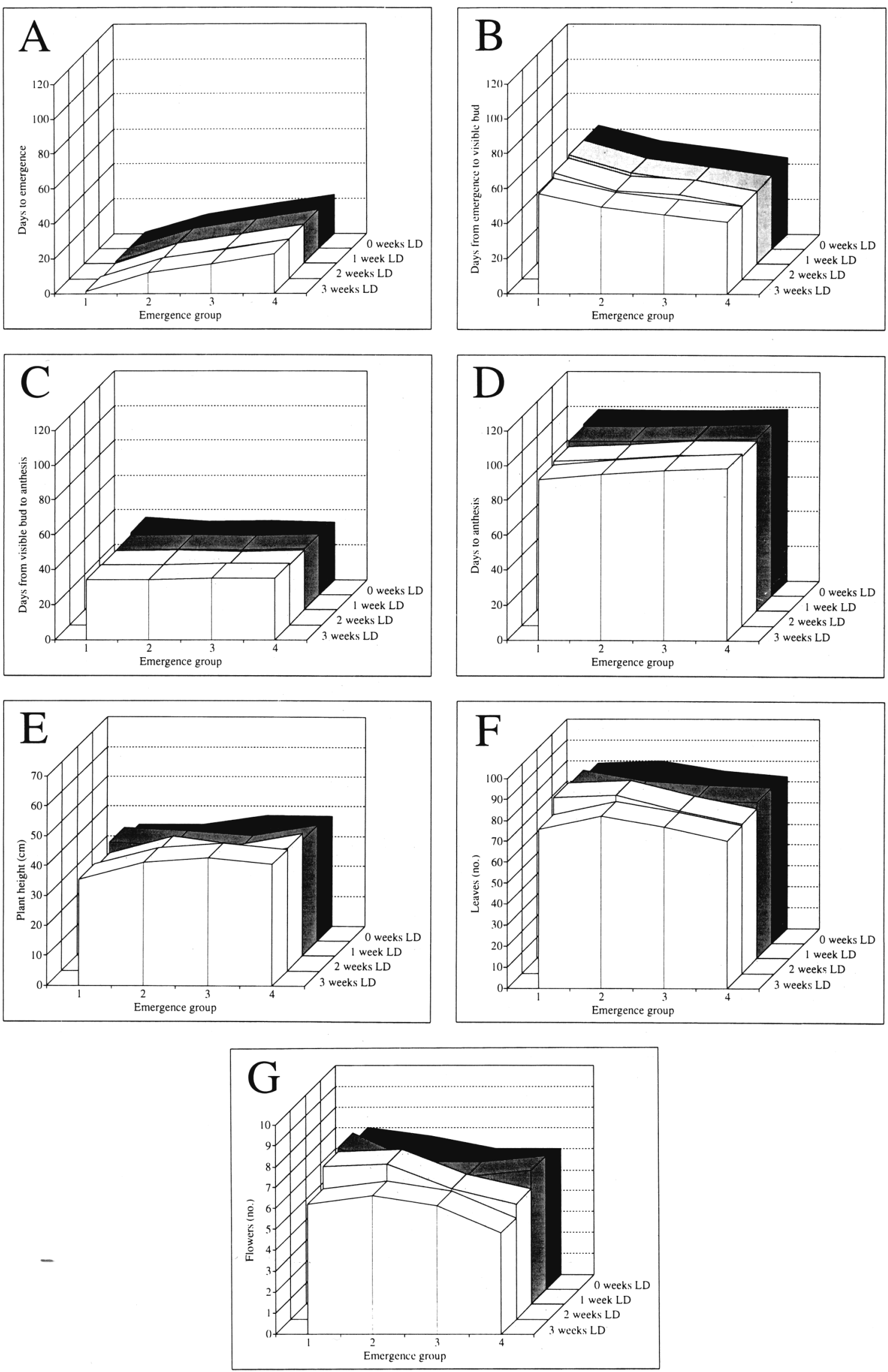

Fig. 1. (A) Average days to emergence from placement in greenhouse and subsequent influence of 0 to 3 weeks of long days (LDs) and emergence group on (B) days from emergence to visible bud, (C) days from visible bud to anthesis, (D) days from placement in greenhouse to anthesis, (E) total plant height, (F) leaf count, and (G) flower count of 'Nellie White' Lilium longiflorum ; Year 2 (1990-91). 
decrease in days to anthesis, since the number of days from visible bud to anthesis either increased by 1 to 2 days or was not influenced by LDs. The leaf unfolding rate apparently was influenced by the LD treatments.

Flower count was not affected by LDs in Year 1 (data not presented) and affected only marginally in Years 2 and 3 (Tables 1 and 2, Fig. 1G, Fig. 2G). Heins et al. (1982) previously noted that 10-day intervals of LDs at various times during a 40-day period after shoot emergence did not influence flower count. In contrast, Smith and Langhans (1962) found that LDs applied from shoot emergence to anthesis decreased flower count at 15.6, 18.3, and 21.1C and Roh and Wilkins ( 1977) found that using incandescent lights for 30 days of daylength extension decreased flower count when compared to natural daylength. These contrasting results probably were due to yearly variations in bulb maturity (Roberts, 1978).

In all years, late-emerging plants reached anthesis from emergence within 3 to 11 days of early-emerging lilies despite a 16- to 22-day difference in the shoot emergence date (Tables 1 and 2, Fig. $1 \mathrm{~A}$ and D, Fig. 2A and D). The difference between early- and late-emerging plants could have been due partially to late-emerging plants' having fewer leaves than early-emerging plants. However, Group 1 plants, the earliest emerging plants, had fewer leaves than Group 2 plants in all 3 years. Despite the difference in leaf count, Group 1 plants took 3 to 9 days longer to reach anthesis from emergence than Group 2 plants.

Bulb size also may have caused late-emerging bulbs to require fewer days from emergence to anthesis than early-emerging bulbs. Lange and Heins (1990) noted a faster leaf unfolding rate for bulbs with greater circumference than smaller bulbs. Plants produced by large bulbs were also taller and had more flowers and leaves than those produced by small bulbs. De Hertogh et al. (1976) found that plants from larger 'Nellie White' bulbs also had more flowers and leaves, but flowered at the same time as smaller bulbs. In addition,
Roberts et al. (1978) noted that bulbs harvested late in the growing season (October) were heavier and, when they were replanted immediately for forcing, emerged quicker than bulbs harvested early in the season (August). Plants produced by the heavier bulbs subsequently flowered earlier, had fewer leaves, and were taller than those produced by the lighter bulbs. In the current study, however, the early-emerging plants reached anthesis from shoot emergence more slowly, had more leaves, and were shorter than late-emerging plants. Thus, while bulb size may have played a role in emergence date, the inconsistency between the results of our studies and those of other studies indicates the need for further research on bulb size and maturity.

Differences in bulb maturity and weight also may have caused the variation between years in response of the Easter lilies to LDs and cold (Roberts et al., 1978, 1985). The Year 3 plants tended to be taller than the plants in Years 1 and 2 (Fig. 1E, Fig. 2E). In addition, while $56 \%$ of the Year 3 bulbs (Table 2) emerged in the first week after placement in the greenhouse, only $12 \%$ of Year 2 bulbs emerged in the first week. Also, no significant interactions $(P \leq 0.05)$ were found for days from emergence to visible bud in Year 2, while significant linear $\times$ linear and quadratic $\times$ quadratic interactions between LDs and cold were found in Year 3 (Tables 1 and 2). Interactions also varied between the years for days from visible bud to anthesis, days to anthesis, plant height, and flower count (Tables 1 and 2). The Year 3 bulbs may have been harvested later in the season than the Year 2 bulbs and may have been more mature than the latter. Roberts et al. (1978) noted that mature bulbs emerged in fewer days, were taller, and exhibited a decreased response to LDs than less-mature bulbs.

In summary, while LDs effectively decreased days to anthesis, the expense and time probably would be justified only for early Easters or very immature bulbs. Three weeks of LDs should be used and excessive elongation prevented by day and night tempera-

Table 2. Main effects and trend analysis of 0 to 3 weeks of long days (LDs) and emergence group on 'Nellie White' Lilium longiflorum, Year 3 (1991-92).

\begin{tabular}{|c|c|c|c|c|c|c|c|c|}
\hline $\begin{array}{l}\text { Weeks of } \\
\text { LDs after } \\
\text { emergence }\end{array}$ & $\begin{array}{c}\text { Emergence } \\
\text { group }^{2}\end{array}$ & $\begin{array}{c}\text { No. } \\
\text { of plants }\end{array}$ & $\begin{array}{l}\text { Days from } \\
\text { emergence to } \\
\text { visible bud }\end{array}$ & $\begin{array}{l}\text { Days from } \\
\text { visible bud } \\
\text { to anthesis }\end{array}$ & $\begin{array}{l}\text { Days to } \\
\text { anthesis }^{y}\end{array}$ & $\begin{array}{c}\text { Plant } \\
\text { ht } \\
(\mathrm{cm})\end{array}$ & $\begin{array}{c}\text { Leaf } \\
\text { count }\end{array}$ & $\begin{array}{c}\text { Flower } \\
\text { count }\end{array}$ \\
\hline$\overline{0}$ & Averaged & 69 & 53.7 & 32.3 & 92.6 & 50.5 & 84.7 & 5.6 \\
\hline 1 & Averaged & 67 & 53.8 & 33.0 & 93.6 & 52.5 & 84.0 & 6.0 \\
\hline 2 & Averaged & 68 & 51.1 & 32.6 & 90.9 & 52.6 & 84.6 & 5.9 \\
\hline 3 & Averaged & 72 & 48.3 & 33.5 & 89.2 & 54.9 & 83.7 & 6.2 \\
\hline \multirow[t]{4}{*}{ Averaged } & 1 & 145 & 55.4 & 32.1 & 87.7 & 50.0 & 83.8 & 5.8 \\
\hline & 2 & 39 & 50.9 & 33.6 & 94.5 & 56.0 & 88.1 & 6.7 \\
\hline & 3 & 41 & 45.6 & 33.8 & 95.8 & 56.6 & 85.3 & 6.3 \\
\hline & 4 & 36 & 42.6 & 33.7 & 98.7 & 55.6 & 78.5 & 5.4 \\
\hline \multicolumn{9}{|l|}{ Weeks of LDs (W) } \\
\hline Linear (L) & & & $0.0001^{x}$ & NS & 0.0001 & 0.0001 & NS & 0.018 \\
\hline Quadratic (Q) & & & 0.001 & NS & 0.048 & NS & NS & NS \\
\hline Residual (R) & & & NS & NS & 0.043 & NS & NS & NS \\
\hline \multicolumn{9}{|l|}{ Emergence group (E) } \\
\hline $\mathbf{L}$ & & & 0.0001 & 0.002 & 0.0001 & 0.0001 & 0.009 & NS \\
\hline Q & & & NS & NS & 0.003 & 0.0001 & 0.0001 & 0.0001 \\
\hline $\mathbf{R}$ & & & NS & NS & NS & NS & NS & NS \\
\hline Significant interactions & & & $\mathbf{L} \times \mathbf{L}$ & None & $\mathrm{L} \times \mathrm{L}$ & $\mathbf{L} \times \mathbf{L}$ & None & $Q \times Q$ \\
\hline$(\mathrm{W} \times \mathrm{E}, P \leq 0.05)$ & & & $Q \times Q$ & & $\mathrm{Q} \times \mathrm{Q}$ & $\mathrm{Q} \times \mathbf{Q}$ & & $R \times L$ \\
\hline & & & & & & $\begin{array}{l}\mathrm{Q} \times \mathrm{R} \\
\mathrm{R} \times \mathrm{L}\end{array}$ & & $\mathrm{L} \times \mathrm{Q}$ \\
\hline
\end{tabular}

${ }^{\mathrm{z}}$ Easter lily plants were separated into four groups based on date of emergence after controlled-temperature forcing and subsequent placement in the greenhouse: $1=0$ to $6,2=7$ to $13,3=14$ to $20,4=21$ to 27 .

${ }^{y}$ From date of placement in greenhouse.

${ }^{x}$ Significance level $(P)$; NS = nonsignificant. 

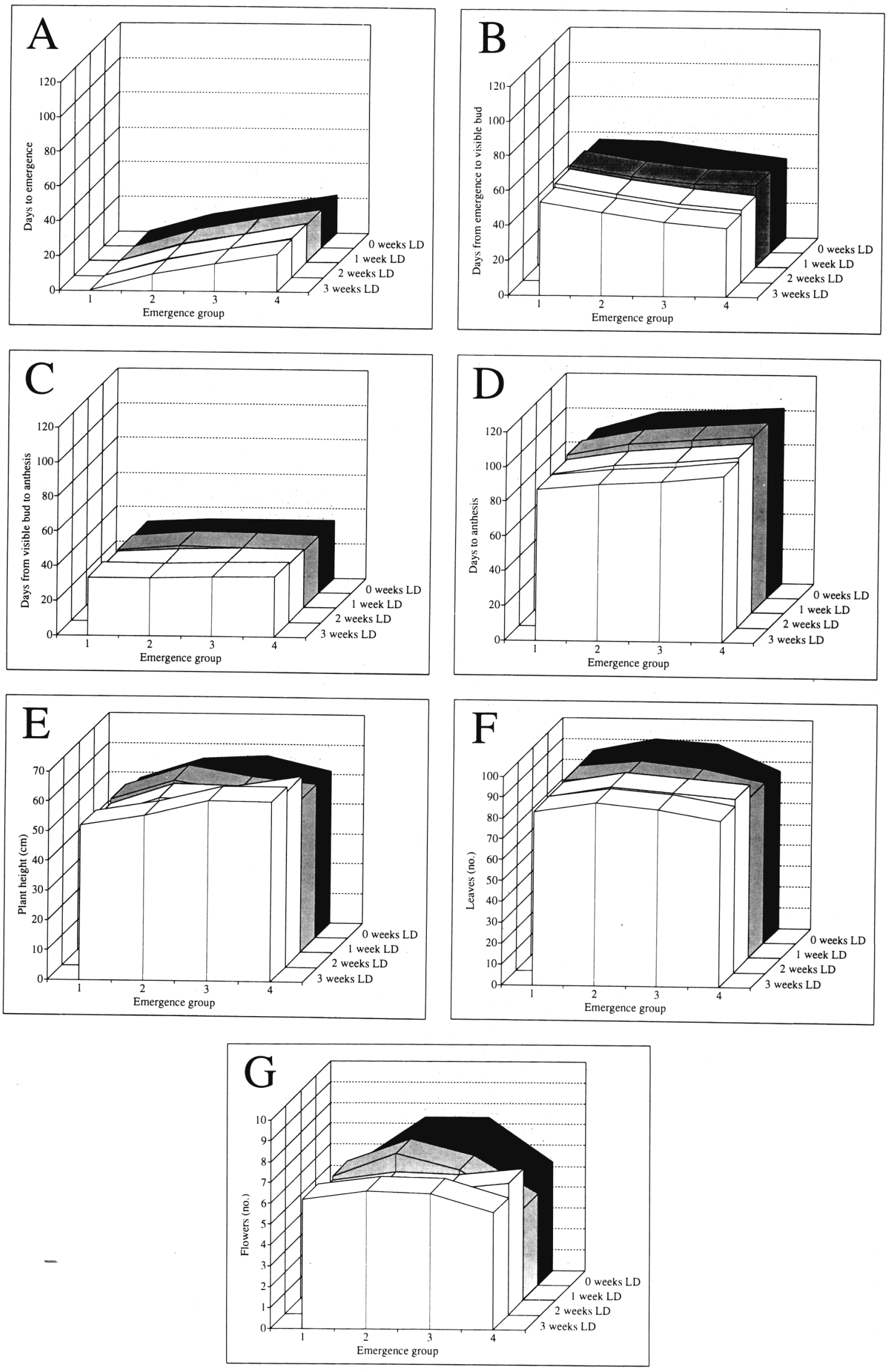

Fig. 2. (A) Average days to emergence from placement in the greenhouse and subsequent influence of 0 to 3 weeks of long days (LD) and emergence group on (B) days from emergence to visible bud, (C) days from visible bud to anthesis, (D) days from placement in the greenhouse to anthesis, (E) total plant height, (F) leaf count, and (G) flower count of 'Nellie White' Lilium longiflorum; Year 3 (1991-92). 
ture manipulation (DIF) or chemical growth retardants (De Hertogh, 1989; Weiler, 1992). Also, Easter lilies do not need to be sorted as early-, middle-, or late-emerging plants when applying LDs. All emergence groups reacted similarly to LDs in Years 1 and 3; while, in Year 2, LDs were least effective on late-emerging lilies. Sorting by emergence date may be helpful, however, in years with an early Easter to speed up late-emerging plants by giving them higher temperatures than the rest of the crop (Weiler, 1992).

\section{Literature Cited}

De Hertogh, A.A. 1989. Holland bulb forcers guide. 4th ed. International Flower-Bulb Centre, Hillegom, The Netherlands.

De Hertogh, A.A., H.P. Rasmussen, and N. Blakely. 1976. Morphological changes and factors influencing shoot apex development of Lilium longiflorum Thunb. during forcing. J. Amer. Soc. Hort. Sci. 101:463-471.

De Hertogh, A.A. and H.F. Wilkins. 1971a. The forcing of northwest-grown

'Ace' and 'Nellie White' lilies. part 1. Florists Rev. 149(3857):29-31.

De Hertogh, A.A. and H.F. Wilkins. 1971b. The forcing of northwest-grown 'Ace' and 'Nellie White' lilies. part 2. Florists Rev. 149(3858):57,104-111.

Heins, R.D., H.F. Wilkins, and W.E. Healy. 1982. The influence of light on lily (Lilium longiflorum Thunb.). II. Influence of photoperiod and light stress on flower number, height, and growth rate. J. Amer. Soc. Hort. Sci. 107:335-338.

Kohl, H.C. and R.L. Nelson. 1963. Daylength and light intensity as independent factors in determining height of Easter lilies. Proc. Amer. Soc. Hort. Sci. 83:808-810.

Lange, N. and R. Heins. 1990. The lowdown on how bulb size influences lily development. GrowerTalks 53:52,54.

Roberts, A.N., J.L. Green, and F.W. Moeller. 1978. Lily bulb harvest maturity indices predict forcing response. J. Amer. Soc. Hort. Sci. 103:827-833.

Roberts, A.N., J.R. Stang, Y.T. Wang, W.R. McCorkle, L.J. Riddle, and
R.W. Moeller. 1985. Easter lily growth and development. Oregon Agr. Expt. Sta. Tech. Bul. 148.

Roh, S.M. and H.F. Wilkins. 1977. The effects of bulb vernalization and shoot photoperiod treatments on growth and flowering of Lilium longiflorum Thunb. cv. 'Nellie White'. J. Amer. Soc. Hort. Sci. 102:229-235.

Smith, D.R. and R.W. Langhans. 1962. The influence of photoperiod on the growth and flowering of Easter lily (Lilium longiflorum Thunb. var. Croft). Proc. Amer. Soc. Hort. Sci. 80:599-604.

Stuart, N.W. 1954. Moisture content of packing medium, temperature and duration of storage as factors in forcing lily bulbs. Proc. Amer. Soc. Hort. Sci. 63:488-494.

Weiler, T.C. 1992. Easter lilies, p. 333-364. In: R.A. Larson (ed.). Introduction of floriculture. Academic Press, New York.

Weiler, T.C. and R.W. Langhans. 1968. Effect of photoperiod on the vernalization requirement of Lilium longiflorum (Thunb.) cv. 'Ace'. Proc. Amer. Soc. Hort. Sci. 93:630-634.

Weiler, T.C. and R.W. Langhans. 1972. Growth and flowering responses of Lilium longiflorum Thunb. 'Ace' to different daylengths. J. Amer. Soc. Hort. Sci. 97:176-177.

Wilkins, H.F. 1980. Easter lilies, p. 327-352. In: R.A. Larson (ed.). Introduction of floriculture. Academic Press, New York.

Wilkins, H.F. 1988. University of Minnesota's step-by-step success 1988-1989 lily forcing season. Minnesota State Florists Bul. 37:6-7.

Wilkins, H.F., W.E. Waters, and R.E. Widmer. 1968a. Influence of temperature and photoperiod on growth and flowering of Easter lilies (Lilium longiflorum Thunb. 'Georgia', 'Ace', and 'Nellie White'). Proc. Amer. Soc. Hort. Sci. 93:640-649.

Wilkins, H.F., R.E. Widmer, and W.E. Waters. 1968b. The influence of carbon dioxide, photoperiod and temperature on growth and flowering of Easter lilies (Lilium longiflorum Thunb. 'Ace' and 'Nellie White'). Proc. Amer. Soc. Hort. Sci. 93:650-654.

Wilkins, H.F., R.E. Widmer, and W.E. Waters. 1970. An insurance policy: Lighting lilies at shoot emergence will overcome inadequate bulb precooling. Florists Rev. 147(3806):60-61, 109. 